\title{
When Trichoscopy Led to the Diagnosis of Non-Scarring Alopecia in Two Teenage Girls
}

\section{Rasso A*, Baybay H, Boukhari K, Elloudi S, Douhi Z and Mernissi FZ}

Department of dermatology CHU Hassan II, Fez, Morocco

*Corresponding author: Dr. Rasso Asmae, Department of dermatology Fez, Morocco, Tel: 212672314910; Email: rassoasmae@gmail.com

\section{Case Report \\ Volume 5 Issue 1}

Received Date: March 11, 2020

Published Date: March 30, 2020

DOI: $10.23880 /$ cdoaj-16000208

\section{Abstract}

Non-scarring alopecia in children and adolescents is a frequent reason for consultation in dermatology, whose etiologies are multiple, the particularity in adolescents that they are a bridge between the child and the adult sometimes gives particular clinical aspects. Case report: Tow adolescents admitted for management of alopecia at the level of the scalp. The clinical examination objectified a non-scarring alopecia front-temporo-parietal in both, without scales or erythema. then trichoscopy showed more specific signs than the clinic and diagnosed trichotillomania and Tinea capitis. Conclusion: the objective of our article is to show two cases of alopecia similar but with differences in trichoscopic aspect and diagnostic, in order to insist on the interest of a good clinical examination followed by a good trichoscopic analysis.

Keywords: Trichotillomania; Tinea capitis; Trichoscopy

\section{Introduction}

The trichoscopy it is a non-invasive tool that allows the recognition of morphologic structures not visible by the naked eye. It is a very well accepted technique and definitively improves the quality of care of patients with alopecia as it reduces the necessity of performing scalp biopsy specimens (1). Our case report on two teenage girls with scalp alopecia.

\section{Case Reports}

Case N1: 14 years old girl, without any pathological history, consulted after appearance of scalp alopecia evolving in the last 2 months, without any notion of medication, toxic or plant application. the examination of the scalp showed a nonscarring fronto-temporo-parietal alopecia, with $17 \mathrm{~cm}$ in size , badly limited, with the presence of scaling, and the hair pull test was positive. The trichoscopy showed a short haircut, flamingo hair, "I" hairs, cadaverous hair, and a circular hair. Mycological study of the hair confirmed a Microsporum canis infection (Figure 1). Treated by oral and topical gresiofulvin with hair regrowth.

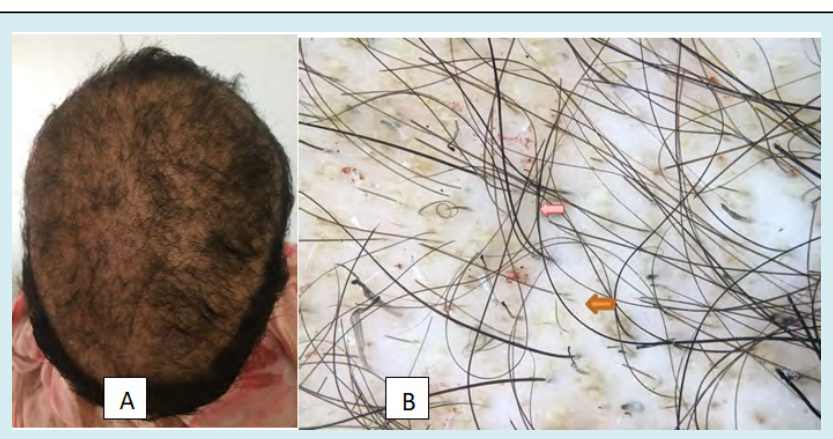

Figure 1: A: non-scarring alopecia front-temporo-parital, B: Trichoscopy with flamingo hair( blue arrow),"I" hairs(green arrow), and a circular hair( pink arrow),cadaverous hair(black arrow). 
Case N2: 12-year-old girl, with no notable pathological history, was consulting for the management of scalp alopecia evolving in the last 8 months, put under several topical and oral anti-mycotic treatments without improvement. Clinical examination revealed a non-scarring alopecia front- temporo-parital, of $10 \mathrm{~cm}$ in size, poorly limited, no erythema or scalp flakes, the hair pull test was negative (Figure 2). The trichoscopy objected hairs cut at different levels, forked hair in "V". A mycological study of the hair was negative, the scalp biopsy confirmed trichotillomania Figure 2.
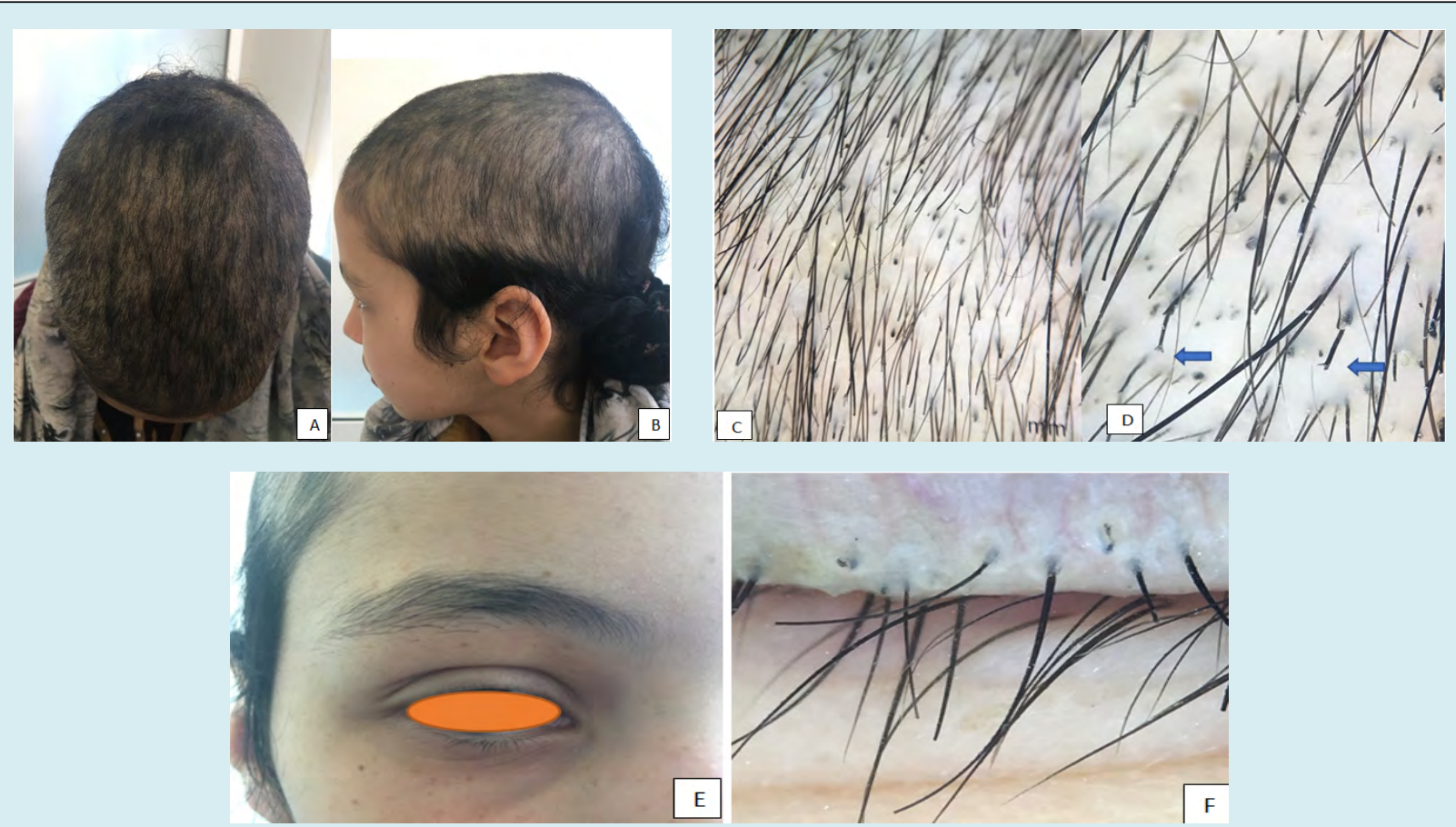

Figur 2: A+B: non-scarring alopecia front-temporo-parital; C: Broken hairs of different lengths; D: split ends (division in Yshaped of the distal part of the hair); E: non-scarring alopecia of eyelashes; F: Black dots (irregular).

\section{Discussion}

Hair loss in Adolescent and children is an important complaint in dermatology clinics and considered as a challenge for dermatologists for reaching a proper diagnosis and therapy for their patients [1].

Tinea capitis is one of the most common causes of hair loss, the diagnosis is often not difficult to recognize due to the presence of redness, hair loss and scaly, itchy scalp margins. But sometimes, the diagnosis is difficult especially in adolescents and adults. So, the trichoscopy which allows a quick and easy analysis and often retains the diagnosis by looking for the zigzag hair, Comma hairs broken and dystrophic hairs, corkscrew hairs, black dots [2,3]. Recently, a new trichoscopic feature has surfaced up It is called "code like-hairs" (bar code-like hairs)[4].

Trichotillomania is a compulsive disorder characterized by repetitive hair pulling that causes noticeable hair loss, generally from the parietal and vertex regions. The disorder most often affects female children (70\%-93\% of cases) between 9 and 13 years of age, who generally deny the habit.
The diagnosis of trichotillomania is often difficult in clinical practice. Various trichoscopic signs have been observed, including broken hairs of different lengths, trichoptilosis, hair powder, hook hairs, coiled hairs, tulip hairs, black dots (irregular) flame hairs are semitransparent, include split ends (division in Y-shaped of the distal part of the hair)[5], and the V-sign (two broken hairs at the same length emerging from the same follicle)[6]. The presence of these trichoscopic signs made it easier for us to retain the diagnosis, but we performed a scalp biopsy and a mycological study before pronouncing the diagnosis to the parents, who often deny this pathology in order to refer them to a psychiatrist for treatment.

\section{Conclusion}

The peculiarity in our two teenage girls is that they presented an identical clinical aspect, and a difference in trichoscopy and diagnosis, this means that trichoscopy, which requires a non-invasive tool to guide the clinic.

Consent: The examination of the patient was conducted according to the Declaration of Helsinki principles. 
Conflict of Interest: I declare no conflict of interest.

\section{References}

1. Khunkhet S, Vachiramon V, Suchonwanit P (2017) Trichoscopic clues for diagnosis of alopecia areata and trichotillomania in Asians. Int J Dermatol 56: 161-165.

2. Hernández-Bel P, Malvehy J, Crocker A, Sánchez-Carazo JL, Febrer I, et al. (2012) Comma hairs: A new dermoscopic marker for tinea capitis. Actas Dermosifiliogr 103(9): 836-837.

3. Miteva M, Tosti A (2012) Altas of Trichoscopy. 33 $3^{\text {rd }}$
(Chapter). Springer-Verlag, London: Springer.

4. Lin Y, Li Y (2014) The dermoscopic comma, zigzag, and bar code-like hairs: Markers of fungal infection of the hair follicles. Dermatol Sin 32(3): 160-163.

5. Martín JM, Montesinos E, Cordero P, Gonzalez V, Ramon D (2019) Trichoscopy features of trichotillomania. Pediatr Dermatol 36(2): 265-267.

6. Rakowska A, Slowinska M, Olszewska M, Rudnicka L (2014) New trichoscopy findings in trichotillomania: flame hairs, V-sign, hook hairs, hair powder, tulip hairs. Acta Derm Venereol 94: 303-306. 